\title{
LA CUSTODIA DEL ARCHIVO DE SAN ISIDORO DE LEÓN COMO FUENTE DE CONFLICTOS EN EL SIGLO XVIII
}

\author{
Elena OSORIO ALONSO
}

\begin{abstract}
RESUMEN: El control del archivo del monasterio de San Isidoro de León se convierte a mediados del siglo XVIII en símbolo de poder y centro de las luchas jurisdiccionales entre el abad y el prior del propio monasterio.

PALABRAS CLAVE: Archivo abacial, monasterio de San Isidoro de León, abad José Antonio de Goyri, colegio de la Compañía de Jesús en León.

ABSTRACT: The custody of San Isidoro's archives in the middle of the eighteenth century becomes a symbol of power and the cause of jurisdiction's battles between the abbot and the prior.
\end{abstract}

KEYWORDS: Abbot's archives, San Isidoro de León monastery, José Antonio de Goyri abbot, Jesuit school in León.

El monasterio de San Isidoro de León cuenta con casi siete siglos de historia ininterrumpida y, como muestra escrita de ello, conserva un importante archivo que ha ido nutriéndose de gran variedad de documentación a lo largo de todos los años de vida de esta insigne institución leonesa ${ }^{1}$. Pero, a pesar de la relevancia de los fondos custodiados en este monasterio, este artículo pretende centrarse en otro

${ }^{1}$ Para una visión general de los fondos custodiados actualmente en este archivo ver PÉREZ PÉREZ, F. I. (2000). "El Archivo de la Real Colegiata de San Isidoro de León”. Promonumenta, n. 4, pp. 6-8. Como catálogo general de este archivo continúa vigente, a pesar de sus errores, PÉREz LLAMAZARES, J. (1923). Catálogo de los códices y documentos de la Real Colegiata de San Isidoro de León. León; ID. (1943). Catálogo de los incunables y libros antiguos, raros y curiosos de la Real Colegiata de San Isidoro de León. Madrid. Para un estudio en profundidad de parte del patrimonio documental y codicológico de este monasterio ver MARTín LÓPEZ, M.E. (1995). Patrimonio cultural de San Isidoro. Documentos ss. X-XIII. León; Domínguez SÁncheZ, S. (1995). Patrimonio cultural de San Isidoro de León. Documentos del siglo XIV. León; SuÁrez GonZÁleZ, A. (1997). Patrimonio cultural de San Isidoro de León. B, Serie bibliográfica, vols. II y III. León. 
aspecto del archivo: su localización y la problemática que de ella se desprende a mediados del siglo XVIII.

En la vida regular del monasterio de San Isidoro se aprecia a lo largo de toda la Edad Moderna una intensa lucha interna de jurisdicciones entre el abad y el prior. Se puede situar el origen de esta confrontación en el hecho de que, mientras el cargo de abad es vitalicio, de nombramiento regio y confirmación pontificia, siendo a menudo designada una persona ajena al monasterio, el prior es nombrado con carácter trienal por el propio cabildo de entre uno de sus miembros, estando completamente inserto en la vida comunitaria y contando con el apoyo de la mayoría de los canónigos. Esta forma tan específica de nombramiento abacial se debe en primer lugar a la exención y dependencia directa del monasterio de San Isidoro de León de la Santa Sede, de ahí que sean necesarias unas bulas de confirmación, pero, además, en el siglo XVIII, época en la que se desarrollan los conflictos expuestos en este trabajo, el patronato regio llega a su máxima expresión, con lo que la elección de abad y su nombramiento se encuentran completamente supeditados a la voluntad regia ${ }^{2}$.

Este conflicto jurisdiccional es la base de casi todos los pleitos que se conocen entre el abad y el prior de San Isidoro de León para la época moderna, siendo uno de los abades más problemáticos en este sentido, aunque no el único, Francisco Gasca Salazar, abad a principios del siglo XVII, quien pretendía cambiar ciertas costumbres del monasterio y tener más funciones de las que tradicionalmente se le habían asignado ${ }^{3}$.

Dentro de esta larga lucha de jurisdicciones se han descubierto gran variedad de quejas y acusaciones, a menudo recurrentes, por parte de ambos contendientes. Sin embargo, no es hasta mediados del siglo XVIII cuando por primera vez aparece como motivo de enfrentamiento entre estos dos poderes la custodia del archivo monástico, tema central de este trabajo.

El abad protagonista absoluto del conflicto es José Antonio de Goyri, quien ostenta el cargo abacial desde 1750 hasta 1771, momento de su fallecimiento. En el propio archivo isidoriano existen noticias de su nombramiento por el rey Fernando

${ }^{2}$ Como culminación del proceso evolutivo del patronato regio se encuentra el Concordato de 1753 entre Benedicto XIV y Fernando VI. Una copia impresa de este documento se conserva en el ASIL, A-b/8-18.

3 OSORIO AlONSO, E. (2006). "La documentación de los nuncios y auditores pontificios: los pleitos de Francisco Gasca Salazar, abad de San Isidoro de León (1599-1621)”. Hispania Sacra. LVIII. 118, pp. 517-544. 
VI ya en el año 1749, pero las bulas de confirmación pontificia son del 9 de enero de $1750^{4}$. Aunque se conocen pocos datos sobre su persona, sin embargo se tienen muchas informaciones sobre su gobierno en la abadía de San Isidoro de León, donde es acusado, desde el comienzo de su mandato, de abusos de poder y de utilizar métodos poco ortodoxos para el cumplimiento de sus órdenes. Además, no sólo existen enfrentamientos con su propia comunidad, sino que también aparecen informaciones sobre un pleito con el obispo leonés sobre el mismo tema jurisdiccional ${ }^{5}$.

Así, en esta amplia situación de lucha de jurisdicciones adquiere gran valor la posesión de los documentos del archivo de San Isidoro como instrumentos de poder. A lo largo de la época moderna, conforme se va consolidando la monarquía absoluta, se desarrolla la idea del archivo como mecanismo que favorece la eficacia administrativa, pero también como mecanismo de poder y dominio. Estas mismas características propias de los archivos reales se pueden extrapolar a este pequeño archivo monástico leonés, donde controlar los libros de cuentas y poseer los privilegios reales y bulas pontificias significa tener el control efectivo del monasterio ${ }^{6}$.

Las primeras noticias sobre el conflicto archivístico datan del 16 de diciembre de 1753, cuando el abad, argumentando problemas sobre la conservación y custodia de los papeles del archivo relativos a la jurisdicción y los derechos de la abadía, expide un auto para que sean restituidos todos los documentos que estén fuera de su lugar correspondiente ${ }^{7}$. El prior cree que el abad se está entrometiendo en su jurisdicción por lo que se opone al mandato, provocando con ello el enfado del abad Goyri, quien censura gravemente tanto al prior como a los canónigos, lo que origina un gran escándalo en toda la ciudad. Ante esta situación el rey tiene que intervenir y, por medio del obispo de Cartagena, Diego de Rojas y Contreras, hace saber al prior y a los canónigos, a través de una real cédula del 2 de enero de

${ }^{4}$ Noticias del nombramiento real en el Archivo de San Isidoro de León (en adelante ASIL), E/213, E/21-4 y E/21-5. Transcripción de los documentos pontificios en OsORIO AlOnso, E. (en prensa). Documentos pontificios del Real monasterio de San Isidoro de León. Siglos XV al XIX. Universidad de León.

${ }^{5}$ ASIL, caja $93, n^{\circ} 15$ y caja $8, n^{\circ} 37$ y 38 .

${ }^{6}$ Sobre las distintas funciones de los archivos de época moderna RoDRíGUEZ DE DIEGO, J.L. (1998). "Archivos del Poder, archivos de la Administración, archivos de la Historia (s. XVI-XVII)". En Generelo J.J. y Moreno LóPez, A. (coords.). Historia de los Archivos y de la Archivística en España. Universidad de Valladolid, pp. 29-42.

${ }^{7}$ ASIL, A/1-17. 
1754, que deben obedecer al abad ${ }^{8}$. Ese mismo mes el prior y los canónigos de San Isidoro responden al rey, a través del mismo obispo, haciéndole saber que aceptan la orden, pero que no se han encontrado documentos fuera de lugar y aprovechan esta respuesta para acusar al abad de utilizar métodos contrarios a las costumbres del monasterio isidoriano 9 : pasó directamente a las penas de derecho (censuras), sin ninguna reconvención o amonestación previa, causando, como se ha señalado anteriormente, el escándalo en toda la ciudad.

Ante las desavenencias existentes entre el abad y el prior de San Isidoro, el rey decide en 1755 organizar el archivo del siguiente modo ${ }^{10}$ : los papeles sobre los derechos y la jurisdicción de la abadía deben ser custodiados en un arca en los palacios abaciales y en caso de vacante de la abadía el arca debe pasar a poder del corregidor de la ciudad, siendo restituida al monasterio en el momento de la toma de posesión de un nuevo abad. Con este mandato queda fijada la división del archivo isidoriano en dos partes: una perteneciente a los asuntos abaciales y otra a los asuntos monásticos, custodiada esta última por el prior y los canónigos de San Isidoro de León.

Esta orden es aceptada por el prior y los canónigos del monasterio, pero ven en ella ciertos inconvenientes que hacen saber al rey ${ }^{11}$. Éste, tras considerar las quejas de los canónigos del monasterio reitera su decisión anterior el día 13 de julio de 1756 con otra real cédula, pero introduce una variante: el arca debe cerrarse con dos llaves diferentes custodiadas ambas por el abad, pero en caso de abadía vacante el corregidor se quedará con una y el prior y los canónigos con otra, para que haya una mayor seguridad ${ }^{12}$.

Ese mismo mes de julio, el prior y los canónigos del monasterio manifiestan su conformidad y el 4 de agosto de 1756, en presencia del escribano público Francisco García Parcero, se reúnen el abad, el prior y los canónigos del monasterio de San Isidoro para cumplir lo dispuesto en dicha real cédula ${ }^{13}$. Así, fueron entregados al abad dos cofres llenos de documentos pertenecientes a la hacienda, frutos y rentas de la abadía y también los documentos referentes a la jurisdicción abacial, tanto

${ }^{8}$ ASIL, A/1-17.

${ }^{9}$ ASIL, A/1-18.

${ }^{10}$ Copias de la real cédula del 22 de mayo de 1755 en ASIL, A /1-20 y A/1-21.

${ }^{11}$ Destacando el hecho de que en período de abadía vacante los documentos quedan a expensas de un poder civil sin posibilidad de intervención del propio monasterio en su custodia y defensa.

${ }^{12}$ ASIL A/1-20 y A/1-21.

${ }^{13}$ ASIL A/1-21. 
temporal como espiritual. Por otra parte, quedaron en el archivo del convento las bulas pontificias, las indulgencias, las donaciones reales y las constituciones de los canonistas conocidos como Navarro, Neroni y Gandarillas, además de algunos documentos conjuntos del abad y del convento, quedando dispuesto que el abad pudiese consultarlos cuando quisiese ${ }^{14}$. Se hace constar en el mismo legajo que recoge esta información que esta selección se había llevado a cabo los días 27, 28 y 29 de julio de ese mismo año 1756.

Con esta división parece que se mantiene la calma en el monasterio, al menos respecto al asunto del control de los documentos, durante un par de años. Pero en 1758 vuelve al primer plano el tema archivístico gracias a una real cédula del 30 de abril por la que se dividen de nuevo los fondos del archivo abacial ${ }^{15}$. En este documento, el rey manda al abad que se ponga de acuerdo con el rector del colegio de la Compañía de Jesús en la ciudad de León para hacer un pequeño archivo fijo en una pared de ese colegio donde se coloquen los documentos reales referentes a la dignidad abacial de San Isidoro, todo ello para la mayor seguridad de estos documentos ${ }^{16}$. Este archivo debe cerrarse con una llave que quedará en manos del abad y en caso de vacar la abadía será dada al corregidor de la ciudad. Además, en caso de vacante de la abadía el rector del colegio jesuita deberá impedir el acceso de cualquier persona a estos documentos. Con fecha del 17 de mayo de 1758 el escribano Francisco García Parcero hizo saber la real cédula al prior y canónigos del monasterio de San Isidoro y éstos contestaron que debían presentar alegaciones a esta orden. Sin embargo, con igual fecha le fue presentado el mismo documento al abad y éste declaró que se disponía a cumplir el mandato. Y así quedaron las cosas. No se conservan actualmente en el archivo isidoriano noticias de los alegatos presentados por los canónigos del monasterio a la orden real, pero lo que resulta seguro es que, si finalmente los hubo, el rey no los tuvo en consideración,

${ }^{14}$ El autor de las principales constituciones de este monasterio leonés a mediados del siglo XVI fue el doctor llamado Navarro, Martín de Azpilcueta, de quien existe una entrada en ALDEA Vaquero, Q., Marín, T. y Vives, J. (1972). Diccionario de Historia Eclesiástica de España. Madrid. pp. 167-169. Tras este personaje existieron otros visitadores-reformadores, como Juan Bautista Neroni a principios de siglo XVII o José de Gandarillas Velasco a finales de ese mismo siglo, pero siempre tomando como base las constituciones de Azpilcueta de 1555.

${ }^{15}$ ASIL, A/1-23.

${ }^{16}$ El Colegio de San Miguel, situado en el barrio de Santa Marina, fue el colegio de la Compañía de Jesús en León desde 1578, año de la inauguración de las instalaciones (desde 1572 ejercían labores educativas en un lugar provisional) hasta la expulsión de los jesuitas en 1767. Más datos sobre esta institución en VIFORCOS MARINAS, M.I. (1997). "La labor educativa del colegio jesuítico de San Miguel de León: huellas de su trascendencia en el nuevo mundo". Tierras de León. XXXVI. 101, pp. 45-67. 
porque el traslado de documentos de San Isidoro al colegio jesuita de León se llevó a cabo ${ }^{17}$.

Vuelve a haber un pequeño período de calma en este monasterio leonés, pero en 1761 hay nuevos mandatos reales relacionados en esta ocasión con la posesión y utilización de los papeles que permanecían en el archivo de San Isidoro ${ }^{18}$. El 17 de septiembre de ese año, el rey Carlos III envió una cédula al abad con motivo de la negativa del prior a enseñar los libros de acuerdos capitulares, que, según los estatutos del monasterio, eran secretos. El abad estaba realizando desde el 3 de julio una visita general a petición del rey y, al negarse el prior a obedecerle en este punto, lo excomulgó. El rey señala en este documento que ya había ocurrido lo mismo en una visita precedente y, finalmente, el prior había enseñado los libros al abad, por lo que ahora debía volver a hacerlo. En este documento el rey señala que si el prior accede a cumplir la voluntad real, se le deberá retirar la excomunión que pesa sobre él, pero si se niega, el abad puede enviarlo a otro monasterio como castigo $^{19}$. En noviembre de ese mismo año vuelve a quejarse el abad ante el rey de que se le ocultan todos los estatutos originales del monasterio, excepto un ejemplar de los de Neroni de 1600, y, al preguntar a los canónigos por su paradero, éstos aseguran no saberlo e incluso ante amenaza de penas canónicas no consiguió ninguna respuesta ${ }^{20}$. Al final, el abad es informado de que los estatutos originales de Navarro están en manos de un notario, pero éste se niega a entregarlos sin una orden real. Este enfrentamiento sobre los estatutos continúa en el año $1762^{21}$, cuando además el abad pretende dar nuevos estatutos, quejándose el prior de que con ellos intenta acabar con su jurisdicción ${ }^{22}$.

${ }^{17}$ Tampoco queda constancia de cómo se realizó ese traslado ni por quién fue supervisado.

${ }^{18}$ ASIL, A/1-25.

${ }^{19}$ El envío de canónigos de San Isidoro de León a otros monasterios como castigo se conoce ya a comienzos del siglo XVII con el abad Gasca Salazar, quien encerraba a sus oponentes en la abadía de Santa María de Benevívere (Palencia).

${ }^{20}$ En ASIL, A/1-26. El abad se refiere en su queja a los estatutos del abad Pedro Zúñiga de 1579 y de Luis Tello de Olivares de 1669, así como a los ya señalados con anterioridad del doctor Navarro (1555) y Neroni (1600).

${ }^{21}$ En esta confrontación el abad es acusado de mentiroso por el canónigo José Meléndez, quien dice que el abad tuvo acceso a los estatutos en el archivo del monasterio, pero no los tuvo por originales. Ante estas acusaciones, el abad presenta su defensa, asegurando que ese canónigo se comporta así por venganza, porque había sido castigado.

${ }^{22}$ Se trata de 15 artículos en los que se aprueban todas las decisiones de Navarro, pero se cambia alguna cláusula, siendo este el motivo de la oposición del prior a su aprobación por el rey. 
El mismo conflicto se repite en 1765, pues, con motivo de la visita anual del abad, vuelven los enfrentamientos sobre los libros capitulares, siendo necesario un documento de la Cámara de enero de 1767, explicando que el prior sólo tiene obligación de dárselos al abad si la visita es ordenada por el rey, no siendo éste el caso $^{23}$.

Con los datos expuestos hasta este momento se puede apreciar la importancia que la posesión de la documentación del monasterio adquiere a la hora de tener el control del mismo; de ahí la continua disputa entre el abad y el prior, ya no sólo por la custodia física de los documentos, sino también por su localización o por la posibilidad de su consulta.

Hasta este momento los continuos conflictos que sufre el monasterio de San Isidoro de León se deben a tensiones exclusivamente internas. Sin embargo, en 1767, se da un acontecimiento externo que también actúa como elemento desestabilizador de la comunidad isidoriana: la expulsión de los jesuitas de los territorios de la Corona española ${ }^{24}$.

Ante este hecho, el 11 de junio de 1767 se expide una real cédula para que se efectúe el traslado del archivo abacial situado en el colegio de los jesuitas de León a San Isidoro con motivo de la expulsión de éstos ${ }^{25}$. Esta cédula está dirigida al alcalde mayor de la ciudad de León, mandándole que se encargue de la devolución de este archivo al convento de donde salió en 1758. Además, le encarga la manera en que debe ser custodiada esta documentación. Debe colocarse dentro de un arca con dos llaves, una en posesión del abad y otra para el prior de San Isidoro ${ }^{26}$. Por último, también se encomienda al alcalde mayor la realización de un inventario completo de los documentos que se custodiaban en ese archivo situado en el

${ }^{23}$ En ASIL, A/1-27, A/1-28, A/1-29 y A/1-30.

24 Es posible consultar los documentos expedidos al respecto en la página web: http://www.cervantesvirtual.com/bib_tematica/jesuitas/seleccion_textos/seleccion_textos2.shtml, donde se encuentra la COLECCIÓN General de Providencias hasta aqui tomadas por el Gobierno sobre el estrañamiento y ocupación de temporalidades de los regulares de la Compañía, que existían en los Dominios de S.M. de España, Indias, e Islas Filipinas, a consequencia del Real Decreto de 27 de febrero, y Pragmática-Sanción de 2 de abril de este año. Madrid: Imprenta Real de la Gazeta, 1767, pp. 1-46. En cuanto a una bibliografía actual sobre el tema, destaca la obra colectiva de GIMÉNEZ LÓPEZ, E. (ed.) (1997). Expulsión y exilio de los jesuitas españoles. Universidad de Alicante.

${ }^{25}$ Real cédula y notificaciones a los interesados en ASIL, A/1-31. Copia del proceso completo en ASIL, A/2-1 y A/2-2.

${ }^{26}$ En caso de abadía vacante la llave del abad debe pasar a manos del alcalde mayor o corregidor de la ciudad hasta la toma de posesión del nuevo abad. 
colegio jesuita. Para la realización de este inventario se pide que se nombre, a conformidad de ambas partes, un perito. Además, se dice que no se admitirán recursos sobre el cumplimiento de este mandato. Así, es notificado al alcalde mayor D. José Fuentes Mangas, quien aceptó todo lo que se le encomendaba y comenzó las notificaciones y los autos para realizar dicha tarea, aunque todo se vio interrumpido por una enfermedad que le tuvo inhabilitado hasta finales de julio. Además, el abad, no conforme con lo ordenado en la real cédula envió una carta con fecha del 6 de julio presentando ante el rey los inconvenientes que él veía ${ }^{27}$ : al estar los documentos en el monasterio no se evita el riesgo de extravío de los mismos en caso de abadía vacante ${ }^{28}$. Además, cree que se impone al abad una servidumbre en el uso de su propio archivo, al tener que depender también del prior $\mathrm{y}$ de dos canónigos archiveros cada vez que quiera consultar sus documentos ${ }^{29}$.

Al recuperarse el alcalde mayor de su enfermedad, a finales de julio, comienza las diligencias para la devolución del archivo al monasterio de San Isidoro y la realización de un completo inventario, pero se encuentra con la oposición del abad, que argumenta su negativa en el hecho de que sus alegaciones ante el rey han sido admitidas en la Cámara, por lo que hay que suspender la ejecución de la cédula del 11 de junio hasta nueva orden ${ }^{30}$. Se cruzan órdenes y continuas negativas hasta que el 27 de octubre de 1767 se recibe una nueva real cédula en la que se ratifica lo dicho en la del 11 de junio, con lo que el abad ya no tiene excusas para negarse a facilitar el acceso del alcalde mayor, el perito Antonio de Nava y Robles y el prior al archivo del colegio de los jesuitas. Esta cédula es notificada al alcalde mayor el 16 de noviembre, pero todavía no se puede llevar a cumplimiento la orden porque surge otro inconveniente que retrasa el proceso. Las partes involucradas en el asunto son citadas el día 18 de noviembre, pero el administrador que tiene las llaves del colegio desde la expulsión de los jesuitas se encuentra ausente de la ciudad y no pueden entrar. Así que hasta el día 21 de noviembre no se comienza el inventario. Ese día se encuentran presentes dos canónigos archivistas delegados del

${ }^{27}$ En ASIL, A/1-32.

${ }^{28} \mathrm{El}$ abad prefiere que el archivo situado en lo que fue el colegio de los jesuitas se traslade a otro convento distinto, como por ejemplo el de San Froilán de recoletos franciscanos, no al monasterio de San Isidoro.

${ }^{29}$ Explica en su argumentación que en ninguna otra iglesia el capítulo tiene intervención en el archivo de la dignidad abacial, poniendo como ejemplo similar a San Isidoro el caso de la colegiata de Roncesvalles.

${ }^{30}$ En ASIL, A/2-1 y A/2-2. Los días 28 y 29 de julio de 1767 se hallan presentes a las puertas del colegio de los jesuitas el alcalde mayor, el perito y el prior esperando la llegada del escribano en compañía del abad, pero en ambas ocasiones el abad se niega a acudir. 
prior; un delegado del abad; el alcalde mayor; el perito Antonio de Nava y Robles y el escribano público que da fe de que todo se lleva a cabo según lo ordenado por el rey. Por fin se completa la devolución del archivo a San Isidoro el día 25 de ese mes, colocándose los documentos en un arca cerrada con dos llaves ${ }^{31}$, una para el abad y otra para el prior.

Todavía faltaba incluir algunos documentos que el abad había sacado y guardado en su casa, con lo que se inventarían también estos papeles y el archivo queda completo el 28 de noviembre, cuando se tienen también las nuevas llaves definitivas y se dan al abad y al prior.

Pero todavía continúan los problemas, porque el abad se niega a que los documentos guardados en un arca en la casa abacial por real cédula de 1756 se incluyan en el nuevo archivo, mientras que el alcalde mayor pide que pasen también a formar parte de éste. Este nuevo enfrentamiento se resuelve con una real cédula del 1 de mayo de 1768 dirigida al alcalde mayor, cargo ostentado en esos momentos por Pablo García de Brizuela, en la que le manda que se reúnan e inventaríen todos los documentos que el abad tuviese separados. Notificado a mediados de mayo a todos los interesados, todos dicen aceptar la orden (tanto el alcalde mayor, como el abad, el prior y los canónigos de San Isidoro) y se comienza el inventario de los documentos a cargo del mismo perito que había realizado el anterior. El trabajo se alarga hasta el 6 de junio de 1768.

Todos estos problemas suscitados por la posesión de los documentos del monasterio no se resolverán ni siquiera con el fallecimiento del abad José Antonio de Goyri, pues, en un inventario hecho a su muerte en 1771, todavía faltan documentos que, en teoría, estaban en su poder y que, según el prior, no aparecen en dicho inventario ${ }^{32}$. Ante esta situación se convoca a los posibles testigos y familiares del abad para interrogarles sobre el paradero de dichos documentos, pero nadie tiene noticia de ellos ${ }^{33}$.

A modo de conclusión se podría decir que el archivo de San Isidoro de León fue protagonista durante quince años de una continua lucha por su control, siendo considerado este hecho como un importante símbolo de poder por el que merece la pena cualquier acusación y enfrentamiento. Hay que destacar que las luchas documentales habían existido siempre, pero es a finales del siglo XVII con los

\footnotetext{
${ }^{31}$ Se especifica que el arca es de nogal.

32 ASIL, E/21-63.

${ }^{33}$ Siendo las constituciones originales de Navarro uno de los documentos desaparecidos.
} 
trabajos de Papenbroeck y Mabillon ${ }^{34}$, padre de la Diplomática, cuando adquieren unos fundamentos teóricos que son utilizados también a la hora de defender la organización archivística del monasterio leonés de San Isidoro en el siglo XVIII ${ }^{35}$.

Además, debido a las especiales características del patronato regio, el conflicto no se circunscribe sólo a la comunidad religiosa y su abad, sino que también se ven implicados los poderes civiles con el soberano a la cabeza, siendo las decisiones de este último vitales para llegar a un cierto entendimiento entre las partes enfrentadas.

Por último, también resulta llamativa la repercusión que estos conflictos tienen en la población de la ciudad de León, que se convierte en espectador implicado en el proceso, pues tanto el abad en sus acusaciones y castigos, como el prior en sus quejas se refieren al escándalo provocado en la ciudad por los enfrentamientos existentes en una institución tan respetada como es el monasterio de San Isidoro de León.

\section{APÉNDICE}

Durante todo este artículo se ha hablado del enfrentamiento entre dos partes; de un lado el abad José Antonio de Goyri y del otro el prior y los canónigos de San Isidoro de León. Esta segunda parte implicada en el conflicto ha sido mencionada durante todo el trabajo de un modo genérico, debido a los diversas personas que participan de ella a lo largo de tan amplio período. Por ello, se ha creído oportuno incluir a modo de apéndice una tabla con los nombres de los distintos priores y canónigos implicados en algunas de estas luchas archivísticas.

${ }^{34}$ Ruiz Asencio, J. M. (2005). "Los orígenes de la Diplomática y la Paleografía como ciencias: Mabillon y el Nouveau Traité". En Reyes Marsilla De PAscual, F. (coord.). Diplomática antigua. Diplomática moderna. Murcia, pp. 15-33.

35 En ASIL, A/1-24 se conserva una carta de un discípulo de un catedrático de Salamanca en la que se defiende la postura del prior y los canónigos de San Isidoro utilizando para ello sólidas bases teóricas y bibliográficas. 


\begin{tabular}{|c|c|c|}
\hline$A \tilde{n} o$ & Prior & Canónigos $^{36}$ \\
\hline 1756 & José Alfonso & $\begin{array}{l}\text { Santiago Orejas } \\
\text { Baltasar de la Bandera } \\
\text { Juan de Robles } \\
\text { José Meléndez } \\
\text { Benito Villafañe } \\
\text { Francisco González } \\
\text { Lucas Canseco } \\
\text { Pedro Morán } \\
\text { Pedro Rodríguez } \\
\text { Antonino Barreda } \\
\text { Marcos Quiñones }\end{array}$ \\
\hline 1758 & Santiago Orejas & $\begin{array}{l}\text { José Meléndez } \\
\text { Benito Villafañe } \\
\text { Pedro Rodríguez } \\
\text { Antonino Barreda } \\
\text { Marcos Canseco } \\
\text { Juan Domingo del Arenal } \\
\text { Pedro Morán } \\
\text { Francisco Pobladura o Poladura }\end{array}$ \\
\hline 1761 & Pedro González Getino & \\
\hline 1767 & Pedro González Getino & $\begin{array}{l}\text { Benito Villafañe } \\
\text { Lucas Canseco (vicetesorero) } \\
\text { Pedro Rodríguez } \\
\text { Antonino Barreda (mayordomo) } \\
\text { Marcos Quiñones (tesorero) } \\
\text { Fernando de Caso (administrador de la } \\
\text { fundación de Misa de Alba) } \\
\text { Francisco Poladura } \\
\text { Pedro Fernández (despensero) } \\
\text { José Parte } \\
\text { Francisco Bezos }\end{array}$ \\
\hline
\end{tabular}

${ }^{36}$ Se reflejan los nombres de los canónigos que aparecen reunidos en capítulo en los momentos de las notificaciones de los documentos que forman parte de este conflicto, pero esto no implica que no hubiese más canónigos en el monasterio, de hecho nunca se dice que estén todos reunidos, sino la mayor parte de ellos. 